\title{
Communication barriers for Sinhala speaking Female Sex Workers (FSW), Men who have Sex with Men (MSM) and Transgender women (TGW) attending central STD clinic Colombo, due to linguistic variations of sexual health related terms: A Qualitative study
}

\author{
Pannala W.S. ${ }^{1}$, Perera P.A.D.M.P. ${ }^{2}$, Godakandaarachchi L.P.P. ${ }^{3}$, Munasinghe I.J. ${ }^{4}$, \\ Jayasuriya S.N. ${ }^{5}$, Weerasinghe G. ${ }^{6}$
}

\begin{abstract}
Introduction: Information regarding sexual health and related issues are of utmost importance to FSW, MSM and TGW as their life styles are deeply bound with them. However, it is difficult to deliver information which mostly goes with medical jargon to populations with lower understanding of them.

Objectives: To describe the linguistic patterns and terms when communicating sex related issues and their variations, among Sinhala speaking FSW, MSM and TGW STD clinic attendees of Colombo and explore barriers in understanding available leaflets for HIV/ STD prevention.

Method: A qualitative study done, using in depth interviews among 8 FSW, 6 MSM and 6 TGW. Transcripts taken were used for exploratory content analysis and coding and analysis of data was done manually.

Results: Several categories of terms, slang words, terms derived from English and scientific words are used to describe external genitalia and sexual behaviors. MSM had higher educational levels and used more English terms. FSW had secondary education, used slang words including names of vegetables to describe the external genitalia. However, they used English derived terms to describe sexual behaviours as they are interacting with clients. TGW had a set of characteristic terms, unique to them and not understood by the others.MSM and TGW understood most terms in leaflets except the medical jargon describing genital tract anatomy. Understanding of leaflets was better for MSM and TGW than FSW. Some members from all groups misinterpreted the term 'unprotected sexual exposure.
\end{abstract}

Conclusion: It is important to consider these linguistic variations when communicating with high risk populations to achieve better understanding and effective health promotion.

Key words: FSW, MSM, TGW, communication barriers, linguistic variations on sexual terms

Authors : Pannala W.S. ${ }^{1}$, Perera P.A.D.M.P. ${ }^{2}$, Godakandaarachchi L.P.P. ${ }^{3}$, Munasinghe I.J. ${ }^{4}$, Jayasuriya S.N. ${ }^{5}$ (MBBS, Pg Dip Venereolgy, MD Venereology; Senior Registrars in Venereology, National STD/AIDS Control Programme, Sri Lanka) Weerasinghe G. ${ }^{6}$ (MD-USSR, MSc, MD, FRCS (Glasg), Consultant Venereologist, National STD/AIDS Control Programme, Sri Lanka)

Copyright

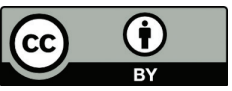

Corresponding author: Pannala W.S. ${ }^{1}$ (warunip@yahoo.com)

Acknowledgement: Director, National STD / AIDS Control Programme, Sri Lanka

Conflict of interest: No conflict of interest

Funding: No funding support for this study

Originality: poster presentation done at annual scientific sessions-2018, Sri Lanka College of Sexual Health and HIV Medicine

Submitted on: 15 11 2018; Accepted on: 20,12.2018 


\section{Full article}

\section{Introduction}

Information regarding sexual health is of utmost importance to female sex workers and men who have sex with men, as their life styles are deeply bound with sex related issues and they are the key population groups at risk for HIV infection. To achieve a healthy sex life as well as to prevent sexually transmitted infections including HIV, this information should be delivered in such a way which is both comprehensive and simple so the targeted population will grasp the important facts which will enable them to achieve maximum good health in this regard. However, it is difficult to deliver the information which mostly goes hand in hand with medical jargon to such population groups. This problem is heightened by the fact that these population groups may be using terms and phrases unique to them when communicating matters related to sex. This might hinder the preventive services by not being able to provide simple information for the purpose of behavioral change communication, leading to disastrous outcomes which could have been alleviated simply by being sensitive to communication barriers due to different linguistic patterns.

The global health sector strategy on HIV 2016 -2021 has a strategic direction on interventions for impact. Under this, a key area to address is, reducing HIV vulnerability, HIV transmission and acquisition. To reduce the vulnerabilities and risk behaviours, one of the activities that should be carried out is behavior change interventions.(1) However communication about sex and sexuality is complex and difficult in all social contexts due to culturally based behavioral guidelines and linguistic taboos unique to individual societies. Therefore, to achieve the desired impact, HIV interventionist should be aware about the languages, the jargons and the slang words these population groups are familiar with. Also, such knowledge will be used effectively when developing the Information, Education and Communication (IEC) material related to sexual health.

On the other hand, as healthcare workers, the understanding of unique words and labels used by key groups to communicate on sex related topics will encourage respect and understanding towards those groups which in turn facilitate STI and HIV prevention and care services. However this area of study was a topic of inadequate research attention and even the little available knowledge will not correctly fit to local setup.

This study was carried out to describe the linguistic patterns and terms when communicating sexuality related issues and their variations, among Sinhala speaking FSW, MSM and TGW STD clinic attendees and to describe barriers in understanding available IEC material for HIV/ STD prevention due to linguistic variations. Ethical approval to conduct the study was received from Ethical review committee, National Hospital of Lanka.

\section{Method}

A Qualitative study done at central STD clinic, Colombo among Sinhala speaking FSW, MSM and TGW clinic attendees. When selecting participants same definition used for Integrated Biological and Behavioral Surveillance Survey were used, that is

FSW - Any female who has sold sex in exchange of money or goods in the past six months. (2)

MSM - A male who have sex with another male as a matter of preference or practice, regardless of their sexual identity or sexual orientation, and irrespective of whether they also have sex with women or not.(2)

Sinhala speaking participants are chosen as Sinhala is the main native language in Sri Lanka and the Central STD clinic is approached mainly by the Sinhala speaking FSWs and MSM due to its geographical location in the capital of Sri Lanka.

Semi-structured, in-depth interviews based on a topic guide were used. Interviews were carried out at the clinic setup, by an investigator while another investigator was taking down transcripts. Both investigators were native Sinhala speakers and also having postgraduate qualifications in the field of venereology and sexual health.

First, participants were shown a diagram of female and male genitalia and inquired to free list all the terms /phrase they used to describe the given anatomical structure. Then names of different sexual behaviours mentioned by the investigator by using common scientific terms in Sinhala and English language and advised them to free list the common terms they use when communicating on such behaviors. Free listing is a method where the interviewer elicits all the items contained in a domain by asking the respondent to list items they feel are contained in that domain.(3) Finally, the 
participants were shown currently available STI/ HIV information leaflets at the STD clinic and explored the participant's understanding of the pre identified key terms on the leaflets. Transcripts taken during the interviews were manually indexed on the basis of recurring themes. The synthesized data were used to content analysis with identifying explanatory accounts, and preliminary typologies where necessary. Purposive sampling until data saturation was obtained and included 8 FSW, 6 MSM and 6 TGW. Participants who gave their informed consent and fallen to the above case definitions were recruited for the study. Participant name was not obtained to make the interviews anonymous.

\section{Results}

There were three groups of participants in this study; female sex workers (FSW), men who have sex with men (MSM) and transgender women (TGW). In general MSM had higher educational level than TGW and FSWs while none of the FSWs had completed their education beyond secondary education.

Findings of the study are presented according to the following analytical typologies; 'terms used to describe male and female genitalia,' 'terms used to describe sexual acts' and 'understanding of currently available IEC materials (leaflets)'. Individual terms used to describe 'male and female genitalia' and 'terms used to describe sexual acts' were either slang words, filthy words, terms derived from English or scientific words and are separately discussed for three participant groups. Some interesting quotes came from the study participants are labeled in terms of their age, whether they were FSW, MSM or TGW.

\section{Terms used to describe male and female genitalia}

All three groups frequently used filthy words to describe, penis, vagina and the anus. They commonly used many other slang words also, to describe genitalia specially the penis. 'Johnse' is one such term used by all three groups to describe penis. MSM used comparatively more English terms and FSW used high amount of slang words including names of vegetables to describe the external genitalia. However, TGW had a set of characteristic terms, unique to them and not understood by the others.

"We have unique terms only understood by our people similar to cults in universities" (TGW Age 24)

\section{Terms used to describe sexual acts}

Generally for the sexual intercourse and especially for anal sex all three groups commonly used filthy words. 'Gal kapanawa' (cutting stones) and 'Athe gahanawa'(hitting by hand ) were very common terms used by all, to describe intercrural sex and masturbation respectively. Interestingly FSWs described sexual intercourse as 'wade'(work) and they described how they satisfy clients by using casual English derived terms.

"We take the client for a 'happy ending' (orgasm) by hand job" ( -Spa based FSW, Age 25)

\section{Understanding of available information, education and communication (IEC) materials}

MSM and TGW understood most terms in leaflets except the medical jargon describing genital tract anatomy like fallopian tubes, ureters. Their understanding of leaflets was also better than FSWs. Although some participants from all three groups understood the term 'unprotected sexual exposure' correctly, significant numbers misinterpreted the phrase 'unprotected sexual exposure' as follows.

"Unprotected sex means prostitution (Age 70, FSW)"

"It means oral sex without condoms (Age 34, FSW)"

"Having sex with unknown person is unprotected sexual exposure (Age 36, FSW-spa based)"

"Unprotected sex means having sex using the orifices that should not use for sex (Age 20, TG)"

The term frequently used in HIV leaflets; 'Bhahira roga lakshana nopenwai' (asymptomatic nature) was not properly understood by some FSWs. Although the Sinhala term for immunity was not completely clear for most of the participants in all three groups, almost everyone had some insight in to that term.

"Immunity is the health we need to day to day life"- Age $24 T G$

"Immunity means no disease" - Age 36 FSW

"Immunity is something inside our body and when it impaired we will get more diseases"- Age 70, FSW 
Table 1: Free listing of terms used for female and male genitalia

\begin{tabular}{|c|c|c|c|}
\hline $\begin{array}{l}\text { Anatomical } \\
\text { structures }\end{array}$ & MSM & FSW & TG \\
\hline Penis & $\begin{array}{l}\text { 'Filth', Malli(Younger } \\
\text { brother),Tool, Cock, Jonse, Polla } \\
\text { (rod), stick }\end{array}$ & $\begin{array}{l}\text { 'Filth'Malli( Younger brother),Pirimi Anga } \\
\text { (Male-body), Jonse, Wambotta (Brinjol) } \\
\text { Kesel (Banana) }\end{array}$ & 'Filth', Jonse, Polla (shaft) \\
\hline Scrotum & Balls, Ata (nuts), Walla (Bunch) & $\begin{array}{l}\text { Balls, Ata (Nuts), Walla (Bunch), Del } \\
\text { (Breadfruit) }\end{array}$ & $\begin{array}{l}\text { Walla (Bunch), Ata } \\
\text { (Nuts), Kosha }\end{array}$ \\
\hline Vagina & Hila (Hole) & $\begin{array}{l}\text { Filth , Nangi (younger sister), Hila, (Hole), } \\
\text { Piyan (shutters) Ganu Anga (Female body), } \\
\text { Yoniya (Vagina) }\end{array}$ & Filth, Poppe \\
\hline Anus & Hila(Hole), Back, Anus, Ass hole & Filth, Passa paththa (Back side) & Poppe \\
\hline Clitoris & Not aware of the term & Ma Ate (Bean seed) & Ma Ate(Bean seed) \\
\hline
\end{tabular}

Table 2: Free listing of terms used to describe sexual acts

\begin{tabular}{|c|c|c|c|}
\hline Acts & MSM & FSW & TGW \\
\hline Sexual intercourse & $\begin{array}{l}\text { "Set wenawa" } \\
\text { "Subject eke innaw" }\end{array}$ & Filth: Sex Karanawa, Wade (work) & $\begin{array}{l}\text { Filth: Johnse kanawa } \\
\text { (eating Johnse), Kotu } \\
\text { paninawa (hopscotch) }\end{array}$ \\
\hline Anal intercourse & Filth & Filth: (Sinhala and English terms) & $\begin{array}{l}\text { Filth: Poppe denawa } \\
\text { (giving poppe) }\end{array}$ \\
\hline Oral intercourse & $\begin{array}{l}\text { Katata denawa } \\
\text { Sindu kiyanawa } \\
\text { (singing songs) }\end{array}$ & $\begin{array}{l}\text { Katata denawa ( giving to mouth), Mouth } \\
\text { suck, Kate arinawa (Discharge to the } \\
\text { mouth) }\end{array}$ & Mouth suck, Blow job \\
\hline Vaginal intercourse & Sutin karanawa & $\begin{array}{l}\text { Sex karanawa, Normal innawa, Athulata } \\
\text { danawa, ( Putting inside) }\end{array}$ & No specific term \\
\hline Intercrural sex & $\begin{array}{l}\text { Gal kapanawa } \\
\text { Deke parak karanawa }\end{array}$ & Gal kapanawa, Kakule gahanawa & Gal kapanawa \\
\hline Masturbation & $\begin{array}{l}\text { Athe gahanawa } \\
\text { (Hand shake) }\end{array}$ & $\begin{array}{l}\text { Athe gahanawa, (Hand shake), Nangiwa } \\
\text { angille gahanawa (fingering to } \\
\text { sister) }\end{array}$ & $\begin{array}{l}\text { Athe gahanawa (Hand } \\
\text { shake) }\end{array}$ \\
\hline Ejaculation & Filth, badu yanawa & $\begin{array}{l}\text { Wathura yanawa, (watering), kiri } \\
\text { yanawa(milking), badu yanawa }\end{array}$ & filth \\
\hline Orgasm & feeling & Happy ending, Full feeling & feeling \\
\hline Foreplay & $\begin{array}{l}\text { Romantic wenawa } \\
\text { (being romantic) }\end{array}$ & Fun ekak denawa, (giving fun) & $\begin{array}{l}\text { Tholak danawa (put the } \\
\text { lip) }\end{array}$ \\
\hline
\end{tabular}




\section{Discussion}

This paper has explored views and experiences on linguistic patterns and terms when communicating sexuality related issues and their variations among key population groups attending the Central STD clinic Colombo. Findings of the study may facilitate understanding of the way to personalize the information that ought to be delivered to these key populations, therefore to achieve the targets in prevention aspects for sexually transmitted diseases and HIV.

When interpreting the findings, it is important to acknowledge its limitations. The sample size was small and derived from key population groups who attended Colombo STD clinic thus findings may therefore not be generalizable to other settings. However the validity of this study was maximized by a 'topic guide' being used and continue interviewing until data saturation achieved.

The words use to communicate about sexuality are reflective of the individual speaker and his educational level in to some extent. In our study MSM and TGW had better educational level in comparison to FSWs and used more English derived terms than FSWs. However English derived term 'Johnse' seems to be common among all three groups to identify penis. Both 'Johnson' and 'John Thomas' is a slang term using for penis especially in British slang language.(4) The word 'Johnse' may be derived from the English word 'John' and its' less offensiveness may be the cause for popularity.

The terms Pirimi anga (male body) and Ganu anga (female body) used to describe penis and vagina were exclusively used by FSW and they seems to be comfortable with those terms when communicating with healthcare workers since the terms are simple and closely resembled scientific terms. However the commonest term they used to describe vagina and penis were Nangi (younger sister) and Malli (younger brother) in day to day conversations. A study done in Cape Town, South Africa among Xhosa speakers, participants similarly used native terms of 'sister' and 'brother' to describe the female and male genitalia reflecting some sort of intercultural euphemism (agreed on words ) towards those words.(3)

On the other hand, MSM never used scientific terms or similar words to describe genitalia and seems to be using more filthy and slang terms comparatively, a finding consistent with existing data that men use more obscene language than women when talking about sex.(5)
Terms used exclusively by males for male genitals could be labeled "power slang" as they tended toward words like 'rod,' 'tool,' 'stick.' In contrast females did not use those terms for male genitals but employed their own vocabulary which could be called "cute euphemisms." Such euphemisms included terms like 'Wambotta' (Brinjol), 'Kesel'(Banana), 'Del' (Breadfruit). Similar findings, that is sexual language influenced by gender roles and power differentials, were mentioned in literature as well.(3)(6)

One main finding that were highlighted during this study was all 3 groups revealed that they use filthy words to explain, penis, vagina, anus and varied sexual acts, sometimes in their day to day conversations regarding sex and they were also not terribly reluctant to mention these terms with the investigators as well.

Even the filthy word when using in numerous contexts, same meaning or unpleasantness might not be there. Thus during in daily encounters with patients especially in STD clinic setups, patients could also be using such terms based on their social and educational background, merely due to the fact that they are not aware of any correct term to explain.

On the other hand, FSWs were using fair amount of English terms regardless of their education background for sexual acts when they were soliciting with the clients. Study done among married couple shed light on association between sexual language used in communication and relationship satisfaction, as well as closeness.(5) Choosing a non-mother tongue during sexual communication is a tactic to reduce threat to 'face' by displacing the topic from the speaker's own language and culture and it also do not hold the same level of emotional impact that a term with the same meaning would have in mother tongue.(3) These may be the reasons behind FSW using more English terms when interacting with clients with whom they do not have emotional relationship and often wants to hide their actual identity from them.

Considering the understanding of leaflets, MSM and TGW understood the leaflet better probably due to better educational level than FSW. However none of the participant understood the highly technical medical jargon used to describe genital tract anatomy. Although medical terms are used in health document as definitive labels for health related behaviours or body parts they lack the same emotional association for the reader who does not have medical knowledge. Therefore people give 
different interpretations for even simple phrases or words used in IEC material based on their personal experience. Even in our study as mentioned above one FSW thinks unprotected sex is prostitution and according to one TGW it is 'sex using unusual orifices', both were deeply bound with their own personal experience.

So, as healthcare workers closely working with HIV prevention and care services we always should cross check and clarify whether the message intended to be given was properly grasped by the client. On the other hand it is necessary to get inputs from key population groups when developing unique IEC materials for them to get the maximum benefit from the limited resources.

\section{Conclusions}

It is important to consider linguistic variations and terminology of the particular group when communicating with high risk populations with regard to sexual health related issues to achieve better understanding and effective health promotion.

\section{References}

1. Global health sector strategy on HIV 2016-2021. Geneva, Switzerland: WHO; 2016. http://www.who.int/hiv/ strategy2016-2021/ghss-hiv/en/ (accessed 15 November 2018).

2. Ministry of Health. Integrated Biological and Behavioral Survey among Key Populations at Higher Risk of HIV in Sri Lanka. 2015.

3. Cain D, Schensul S, Mlobeli R. Language choice and sexual communication among Xhosa speakers in Cape Town, South Africa: Implications for HIV prevention message development. Health Educ Res. 2011;26(3):47688.

4. Urban dictionary. https://www.urbandictionary .com/ define.php?term=John\%20Thomas (accessed 13 November 2018)

5. Hess J A, Coffelt T. Verbal Communication about Sex in Marriage: Patterns of Language Use and Its Connection with Relational Outcomes. The Journal of Sex Research 2011; 49(6): .

6. Sanders JS, Robinson WL. Talking and Not Talking About Sex: Male and Female Vocabularies. Journal of Communication 1979; spring 1979(): 